Original Research Article

\title{
Knowledge and attitude towards emergency contraception among undergraduate medical students
}

\author{
Aditya N. Gajera', Manish J. Barvaliya², Apexa Shukla ${ }^{3}$, C. B. Tripathi' ${ }^{2 *}$
}

${ }^{1}$ Government Medical College, Bhavnagar, Gujarat, India

${ }^{2}$ Department of Pharmacology, Government Medical College, Bhavnagar, Gujarat, India ${ }^{3}$ Department of Pharmacology, Gujarat Medical Education and Research Society Medical College, Dharpur, Patan, Gujarat, India

Received: 04 February 2017 Accepted: 02 March 2017

\section{*Correspondence to:}

Dr. C. B. Tripathi,

Email: cbrtripathi@yahoo.co.in

Copyright: (C) the author(s), publisher and licensee Medip Academy. This is an openaccess article distributed under the terms of the Creative Commons Attribution NonCommercial License, which permits unrestricted noncommercial use, distribution, and reproduction in any medium, provided the original work is properly cited.

\begin{abstract}
Background: Studying the knowledge and attitude of medical students towards emergency contraception, as they are the future medical professionals and they will serve as the main channel for providing proper knowledge and making positive impression of it in general population. The objective of the study was to assess the knowledge and attitude of undergraduate medical students towards emergency contraception.

Methods: Medical students were given pre-validated questionnaire and divided in two groups. Group A students did not learn about emergency contraception, whereas group B students learnt about it. Interview of both groups were conducted separately. For group A, 1 hour seminar was conducted and after 7 days, same questionnaire was provided again for data collection.

Results: 154 students were included in group A whereas 162 students in group B. Average knowledge and attitude was significantly increased after seminar in group A [knowledge $41 \pm 16.88 \%$ vs. 59.32 $\pm 14.46 \% ; \quad \mathrm{P}<0.05$; attitude $36.24 \pm 10.93$ vs. $41.5 \pm 10.87$; $<<0.05$ ]. Average knowledge of group B students was $64.73 \pm 12.15 \%$ whereas average attitude score was $42.9 \pm 9.79$. Amongst all, $86.4 \%, 87 \%$ and $89.3 \%$ students were not able to describe about emergency contraception, different methods and advantages of intra-uterine device as emergency contraception, respectively. There are $82.1 \%$ students showed positive interest in learning more about emergency contraception and $70.1 \%$ agreed to recommend its use in future. Students having good knowledge showed more positive attitude towards emergency contraception $[\mathrm{r}=0.41, \mathrm{P}<0.05]$.

Conclusions: Students have poor knowledge of special issues arises with emergency contraception. Proper attention should be given to these aspects during their teaching. Students have shown their positive interest to learn more about emergency contraception. Objective based seminar will be more helpful in improving knowledge and attitude.
\end{abstract}

Keywords: Emergency contraception, KAP study, Medical students, Unwanted pregnancy

\section{INTRODUCTION}

Emergency Contraception (EC) is a method of contraception used to prevent unintended pregnancy following unprotected intercourse or expected failure of contraception. $^{1}$ Despite availability of different contraceptive methods, unintended pregnancies continue to occur. Reasons for such pregnancies may be lack of awareness, negative attitude to contraception, low accessibility, sexual assault and/or rarely failure of contraception. $^{2}$ According to WHO, UNICEF and UNFPA estimates for the years 1990, 1995 and 2000, more than 50 million women die of pregnancy related complications every year. ${ }^{3}$ EC plays a vital role in preventing unintended pregnancy and unsafe abortion. ${ }^{2}$ If used after contraception failure, Emergency Contraception Pills (ECPs) could prevent $50 \%$ of unintended pregnancies. ${ }^{4}$ Given increasing adolescent sexual activity and decreasing age at first sex in developing countries the use of EC is especially important. $^{5}$ Medical students are future health care providers of the country. Their knowledge and attitude towards EC can affect the attitude of large number of population towards EC to whom they will deal in future. 
Therefore, to provide them proper training in such special issues, it is very important to know their current knowledge and attitude towards EC. Various studies have been conducted to evaluate knowledge and attitude of health and medical professionals towards EC. The present study is designed to evaluate the knowledge and attitude of medical students towards EC.

\section{METHODS}

After approval from Institutional Review Board (IRB), Government Medical College, Bhavnagar, Gujarat, India, undergraduate medical students from first year through third part II year were invited for the study. Those who gave the written informed consent were included in study and given questionnaire. Questionnaire was made by giving due consideration to knowledge and attitude of medical students towards EC. The majority questionnaires were prepared from the previously published studies to increase the quality and validity of the data and their easy comparability with other populations., 2 Questionnaire was validated by two subject experts who are practicing physician and professor, having post-graduation in gynaecology and pharmacology, respectively. Questionnaire was tested on small group of students before applying to the study participants. Questionnaire was consisted of total 44 questions on demographics $(n=14$, no. 1 to 14$)$, knowledge ( $n=15$, no. 15 to 29$)$, and attitudes $(n=15$, no. 30 to 44 ). Students were provided $45 \mathrm{mins}$ to complete the questionnaire. Students were divided in to two groups in response to question no. 11. Group A included students who did not learn about EC whereas Group B students learnt about EC through the topics covered in pharmacology, community medicine and gynaecology under their regular curriculum. Interview of both groups were conducted separately. For the participants of Group A, 1 hour seminar was conducted on EC after collecting filled in questionnaire. After 7 days of conducting seminar, same questionnaire was provided again to Group A.

\section{Outcome Measures and Statistical Consideration}

Data were expressed in proportions and descriptive statistics was used. Each knowledge question was evaluated for correct answer, amongst which subjective questions evaluated according to predetermined scoring and objective questions considered right if the answer is correct and wrong if incorrect or answered as "Don't' know". Adequate knowledge was considered when score was $\geq 75 \%$. Attitude score was calculated out of 75 after reversing the score for positive attitude questions. (Higher the score is better attitude) Comparisons of knowledge and attitude in participants of group A before and after seminar was performed using paired t-test and Wilcoxon matched pairs signed rank test, respectively. Comparisons of knowledge and attitude between participants of group A2 and B was done using unpaired t-test and Mann Whitney $U$ test, respectively. Effect of demographic variables on knowledge of study participants was evaluated by using Chi-square test. Regression analysis was performed to check correlation between knowledge and attitude of participants using linear regression model. Correlation coefficient was calculated and correlation was checked by using Spearman $r$ test. All statistical analysis was done using GraphPadInstat3 software demo version. $\mathrm{P}<0.05$ was considered significant.

\section{RESULTS}

\section{Demographic data}

Total 316 undergraduate medical students participated. Group A had 154 (48.73\%) students and 162 (51.26\%) were enrolled in group B. Group A students were belong to first and second M.B.B.S. whereas group B students were from third first and final year M.B.B.S. Group A students were analyzed twice based on questionnaire filled by them before and 7 days after attending the seminar. Of 154 students, 146 (94.80\%) students attended the post lecture session. Demographic details of study participants are given in Table 1. Figure 1 shows flow chart of study participants.

\section{Assessment of knowledge and attitude}

Of 154 participants in Group A1, 02 (1.3\%) participants were having adequate knowledge about EC. After 7 days of conducting seminar, $20(13.70 \%)$ out of 146 participants showed adequate knowledge. Among Group $\mathrm{B}$ participants who have previously attended lecture or seminar, $36(22.22 \%)$ of 162 showed adequate knowledge. Of 308 total participants, 86.4\%, 87\% and $89.3 \%$ participants were not able to describe about EC, different methods of EC and advantages of IUD over EC pills, respectively. Average knowledge of participants of Group A1 was significantly increased after 1 hour seminar $(41 \pm 16.88 \%$ vs. $59.32 \pm 14.46 \%$; $\mathrm{P}<0.05$, Figure 2) however, it was not achieved up to the level of Group B. Average knowledge of participants of Group B was $64.73 \pm 12.15 \%$ and that was significantly higher than Group A2 (Figure 3). Evaluation of individual questions is shown in Table 2. Effect of various demographic variables on knowledge about EC of all 308 (Group A2+B) participants is shown in Table 3. Academic year had significant impact on adequate knowledge of study participants. More number of participants had adequate knowledge among third year students and intern doctors as compared to first and second year students. $(\mathrm{P}<0.05)$ Overall attitude of study participants was assessed by calculating attitude score. Average attitude score was $42.23 \pm 10.33$ (out of total score of 75 ). Attitude score in Group A was significantly improved after attending seminar (36.24 \pm 10.93 vs. $41.5 \pm 10.87 ; \mathrm{P}<0.05$, Figure 2$)$. It was equivalent to study participants of Group B (41.5 \pm 10.87 vs. $42.9 \pm 9.79$; P>0.05, Figure 3$)$. Significant correlation was found between knowledge and attitude of study participants. 
Table 1: Demographic details of study participants.

\begin{tabular}{|c|c|c|c|c|}
\hline \multirow{2}{*}{\multicolumn{2}{|c|}{ Demographic variables }} & \multicolumn{2}{|l|}{ Group A } & \multirow{2}{*}{ Group B $(n=162)$} \\
\hline & & Group A1 (n=154) & \multirow{2}{*}{$\begin{array}{l}\text { Group A2 }(\mathbf{n}=\mathbf{1 4 6}) \\
18.3 \pm 0.7\end{array}$} & \\
\hline Age in years & & $18.3 \pm 0.8$ & & $21.0 \pm 1.1$ \\
\hline \multirow[t]{2}{*}{ Gender } & Male & $74(48.1)$ & $66(45.2)$ & $88(54.3)$ \\
\hline & Female & $80(51.9)$ & $80(54.8)$ & $74(45.7)$ \\
\hline \multirow{5}{*}{ Academic year } & First year & $100(64.9)$ & $100(68.5)$ & 00 \\
\hline & Second year & $54(35.1)$ & $46(31.5)$ & 00 \\
\hline & Third First & 00 & 00 & $85(52.5)$ \\
\hline & Third Final & 00 & 00 & $57(35.2)$ \\
\hline & Internship & 00 & 00 & $20(12.3)$ \\
\hline \multirow{4}{*}{ Marital Status } & Married & 00 & 00 & 00 \\
\hline & Single & $153(99.4)$ & $146(100)$ & $154(95.1)$ \\
\hline & Engaged & $01(0.6)$ & 00 & $07(4.3)$ \\
\hline & Not attempted & 00 & 00 & $01(0.6)$ \\
\hline \multirow{8}{*}{ Religion } & Hindu & $144(93.5)$ & $138(94.5)$ & $149(92.1)$ \\
\hline & Muslim & $02(1.3)$ & $02(1.4)$ & $07(4.4)$ \\
\hline & Jain & $08(5.2)$ & $06(4.1)$ & $04(2.5)$ \\
\hline & Christian & 00 & 00 & 00 \\
\hline & Shikh & 00 & 00 & 00 \\
\hline & Parsi & 00 & 00 & 00 \\
\hline & Budhdhist & 00 & 00 & 00 \\
\hline & Others & 00 & 00 & 02 \\
\hline \multirow{3}{*}{ Domicile } & Urban & $113(73.4)$ & $105(72.0)$ & $136(84.0)$ \\
\hline & Rural & $24(15.6)$ & $31(21.2)$ & $23(14.1)$ \\
\hline & Not attempted & $17(11.0)$ & $10(6.8)$ & $03(1.9)$ \\
\hline \multirow{3}{*}{ Type of family } & Nuclear & $99(64.3)$ & $98(67.1)$ & $124(76.5)$ \\
\hline & Joint & $49(31.8)$ & $42(28.8)$ & $33(20.4)$ \\
\hline & Not attempted & $06(3.9)$ & $06(4.1)$ & $05(3.1)$ \\
\hline \multirow{5}{*}{ Living with } & Parents & $25(16.2)$ & $25(17.1)$ & $43(26.5)$ \\
\hline & Hostel & $128(83.1)$ & $120(82.2)$ & $117(72.2)$ \\
\hline & Renting with friends & 00 & 00 & $01(0.65)$ \\
\hline & Husband/wife & 00 & 00 & 00 \\
\hline & Others & $01(0.7)$ & $01(0.7)$ & $01(0.65)$ \\
\hline \multirow{5}{*}{ Father's education } & Secondary & $28(18.2)$ & $28(19.2)$ & $26(16)$ \\
\hline & Higher secondary & $12(7.8)$ & $12(8.2)$ & $10(6.2)$ \\
\hline & Graduate & $79(51.3)$ & $77(52.7)$ & $91(56.2)$ \\
\hline & Post graduate & $32(20.8)$ & $25(17.1)$ & $25(15.4)$ \\
\hline & Not attempted & $03(1.9)$ & $04(2.8)$ & $10(6.2)$ \\
\hline \multirow{5}{*}{ Mother's education } & Secondary & $39(25.3)$ & $39(26.7)$ & $42(25.9)$ \\
\hline & Higher secondary & $18(11.7)$ & $18(12.3)$ & $20(12.3)$ \\
\hline & Graduate & $66(42.9)$ & $62(42.4)$ & $59(36.4)$ \\
\hline & Post graduate & $14(9.1)$ & $10(6.8)$ & $13(8)$ \\
\hline & Not attempted & $17(11.0)$ & $17(11.6)$ & $28(17.3)$ \\
\hline \multirow[t]{2}{*}{ Heard about EC } & Yes & $88(57.1)$ & $146(100)$ & $162(100)$ \\
\hline & No & $66(42.9)$ & 00 & 00 \\
\hline \multirow{4}{*}{ Time heard about EC } & $<6$ months & $59(38.3)$ & $139(95.2)$ & $53(32.7)$ \\
\hline & 6 months- 5 years & $34(22.1)$ & $05(3.4)$ & $85(52.5)$ \\
\hline & Before 5 years & $02(1.3)$ & 00 & $21(13.0)$ \\
\hline & Not attempted & $59(38.3)$ & $02(1.4)$ & $03(1.8)$ \\
\hline \multirow{6}{*}{$\begin{array}{l}\text { Source of information } \\
\text { about EC }\end{array}$} & Formal education & $38(24.7)$ & $98(67.1)$ & $136(84.0)$ \\
\hline & Media & $37(24)$ & $36(24.7)$ & $69(42.6)$ \\
\hline & Magazine & $15(9.7)$ & $32(21.9)$ & $36(22.2)$ \\
\hline & Internet & $19(12.3)$ & $35(24)$ & $36(22.2)$ \\
\hline & Health facilities & $05(3.2)$ & $18(12.3)$ & $49(30.2)$ \\
\hline & Friends/Relative & $31(20.1)$ & $33(22.6)$ & $55(34)$ \\
\hline
\end{tabular}


Table 2: Evaluation of knowledge questions in study participants of various groups.

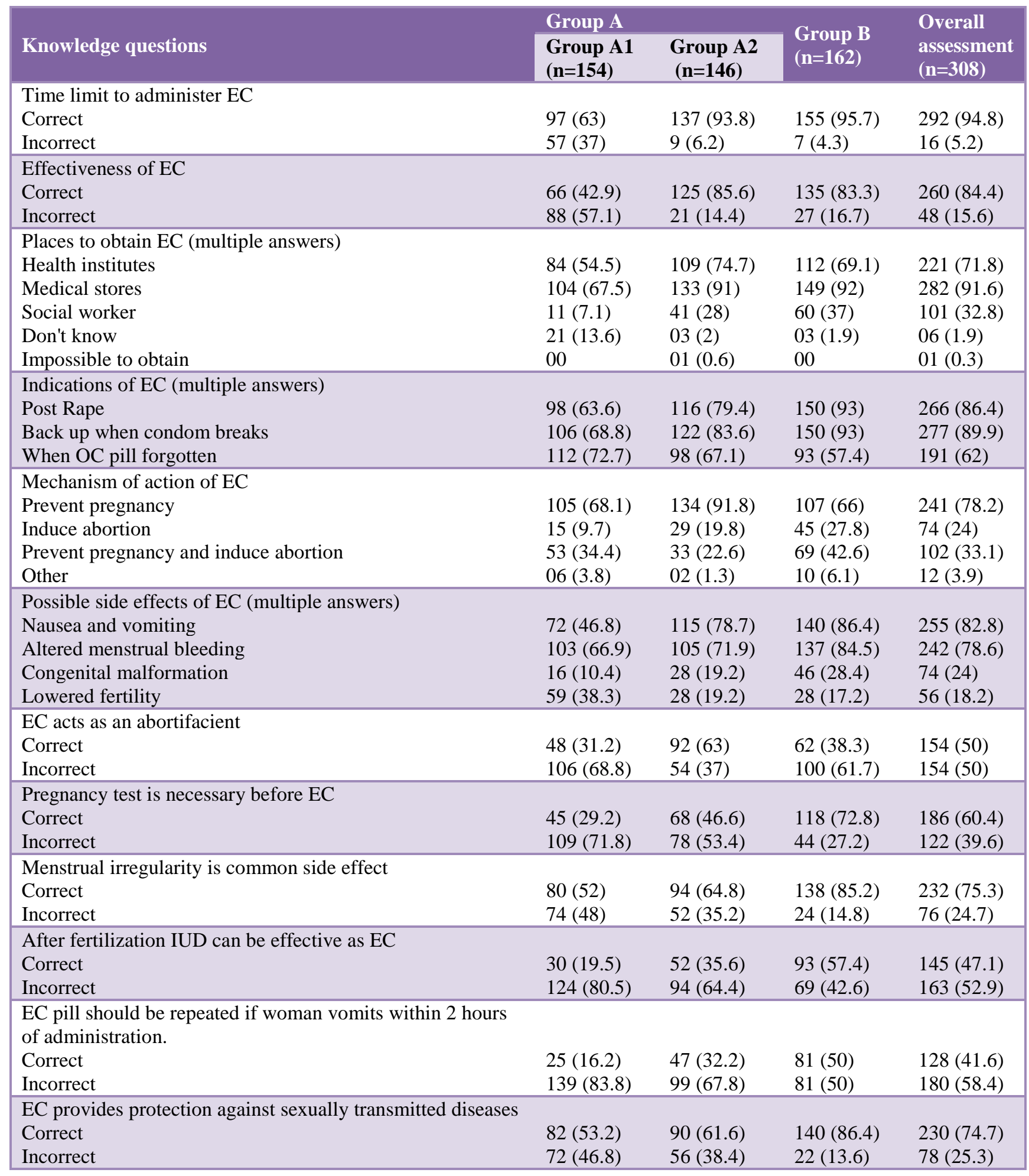

Participants having good knowledge showed more positive attitude towards EC. There are $(\mathrm{r}=0.41, \mathrm{P}<0.05$, Figure $4, n=308) 74.35 \%$ participants did not have any ethical or religious issues for suggesting EC. Amongst all $23 \%$ participants were not able to judge about suggesting EC to everyone in future whereas $38.5 \%$ participants denied suggesting EC to everyone. Those participants who had positive attitude towards the benefits of EC against its risk were $63.6 \%$. EC is appropriate for discussion with friends and family is believed by $83.1 \%$ of participants. Use of EC discourages the regular contraceptive use was considered true according to $37.1 \%$ whereas $28.2 \%$ participants were not able to judge the issue. Those who disagreed to the statement that EC may 
affect pregnancy in future were $43.5 \%$ whereas $22.1 \%$ were not able to decide their attitude. EC should be more widely advertised is believed by $73.7 \%$ of participants whereas $58.1 \%$ believed that EC should be available without prescription. EC promotes promiscuity, agreed by $29.5 \%$ participants whereas $19.2 \%$ were neutral. Amongst all, $70.1 \%$ and $37.7 \%$ participants dis-agree the statement that EC should be available to victims of rape only and women over 18 years, respectively. Those who showed positive interest in learning more about EC were $82.1 \%$ whereas $70.1 \%$ agreed to recommend use of EC in future.

\section{DISCUSSION}

Unwanted pregnancy has adverse impact on social and health outcomes in developing countries. ${ }^{7} \mathrm{EC}$ helps in preventing pregnancy when routine contraception fails and unprotected intercourse happens. ECPs are effective within 72 hours after intercourse, but recent studies have confirmed that they are effective for up to 120 hours. ${ }^{8,9}$

Table 3: Effect of demographic variables on knowledge of all study participants.

\begin{tabular}{|c|c|c|c|c|}
\hline & Demographic variables & $\begin{array}{l}\text { Adequate } \\
\text { knowledge }\end{array}$ & $\begin{array}{l}\text { Inadequate } \\
\text { knowledge }\end{array}$ & $\begin{array}{l}\text { P value } \\
(n=308)\end{array}$ \\
\hline \multirow[t]{2}{*}{ Gender } & Male & $25(8.1)$ & $129(41.9)$ & \multirow{2}{*}{0.46} \\
\hline & Female & $31(10.1)$ & $123(39.9)$ & \\
\hline \multirow{5}{*}{ Academic year } & First year & $9(2.9)$ & $91(29.5)$ & \multirow{5}{*}{0.019} \\
\hline & Second year & $11(3.6)$ & $35(11.4)$ & \\
\hline & Third First & $12(3.9)$ & $73(23.7)$ & \\
\hline & Third Final & $19(6.2)$ & $38(12.3)$ & \\
\hline & Internship & $5(1.6)$ & $15(4.9)$ & \\
\hline \multirow{3}{*}{ Marital Status } & Single & $55(17.9)$ & $245(79.6)$ & \multirow{3}{*}{0.67} \\
\hline & Engaged & $1(0.3)$ & $6(1.9)$ & \\
\hline & Not attempted & 0 & $1(0.3)$ & \\
\hline \multirow{4}{*}{ Religion } & Hindu & $50(16.3)$ & $237(76.9)$ & \multirow{4}{*}{0.08} \\
\hline & Muslim & $1(0.3)$ & $8(2.6)$ & \\
\hline & Jain & $5(1.6)$ & $5(1.6)$ & \\
\hline & Others & 0 & $2(0.7)$ & \\
\hline \multirow{3}{*}{ Domicile } & Urban & $49(15.8)$ & $192(62.3)$ & \multirow{3}{*}{0.15} \\
\hline & Rural & $5(1.6)$ & $49(15.8)$ & \\
\hline & Not attempted & $2(0.7)$ & $11(3.8)$ & \\
\hline \multirow{3}{*}{ Type of family } & Nuclear & $45(14.6)$ & $177(57.5)$ & \multirow{3}{*}{0.27} \\
\hline & Joint & $9(2.9)$ & $66(21.4)$ & \\
\hline & Not attempted & $2(0.7)$ & $9(2.9)$ & \\
\hline \multirow{4}{*}{ Living with } & Parents & $13(4.1)$ & $55(17.9)$ & \multirow{4}{*}{0.96} \\
\hline & Hostel & $43(14)$ & $194(63)$ & \\
\hline & Renting with friends & 0 & $1(0.3)$ & \\
\hline & Others & 0 & $2(0.7)$ & \\
\hline \multirow{5}{*}{ Father's education } & Secondary & $15(4.9)$ & $39(12.7)$ & \multirow{5}{*}{0.17} \\
\hline & Higher secondary & $2(0.7)$ & $20(6.5)$ & \\
\hline & Graduate & $25(8.1)$ & $143(46.4)$ & \\
\hline & Post graduate & $11(3.6)$ & $39(12.7)$ & \\
\hline & Not attempted & $3(1)$ & $11(3.6)$ & \\
\hline \multirow{5}{*}{ Mother's education } & Secondary & $18(5.8)$ & $63(20.5)$ & \multirow{5}{*}{0.19} \\
\hline & Higher secondary & $6(1.9)$ & $32(10.4)$ & \\
\hline & Graduate & $21(6.8)$ & $100(32.5)$ & \\
\hline & Post graduate & $7(2.3)$ & $16(5.2)$ & \\
\hline & Not attempted & $4(1.3)$ & $41(13.3)$ & \\
\hline \multirow{4}{*}{ Time heard about EC } & $<6$ months & $30(9.7)$ & $162(52.6)$ & \multirow{4}{*}{0.33} \\
\hline & 6 months- 5 years & $19(6.2)$ & $71(23.1)$ & \\
\hline & Before 5 years & $5(1.6)$ & $16(5.1)$ & \\
\hline & Not attempted & $2(0.7)$ & $3(1)$ & \\
\hline \multirow{6}{*}{$\begin{array}{l}\text { Source of information } \\
\text { about EC }\end{array}$} & Formal education & $49(15.9)$ & $185(60.1)$ & \multirow{6}{*}{0.67} \\
\hline & Media & $26(8.4)$ & $79(25.6)$ & \\
\hline & Magazine & $11(3.6)$ & $57(18.5)$ & \\
\hline & Internet & $14(4.5)$ & $57(18.5)$ & \\
\hline & Health facilities & $13(4.2)$ & $54(17.5)$ & \\
\hline & Friends/Relative & $14(4.5)$ & $74(24)$ & \\
\hline
\end{tabular}




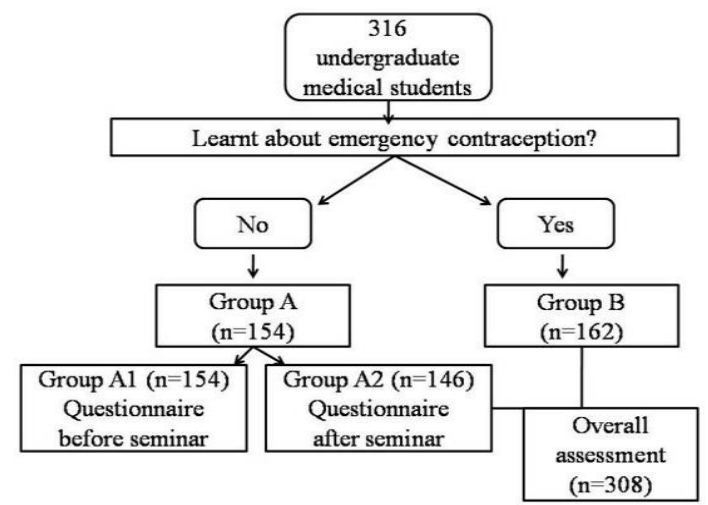

Figure 1: Flow chart of study participants.

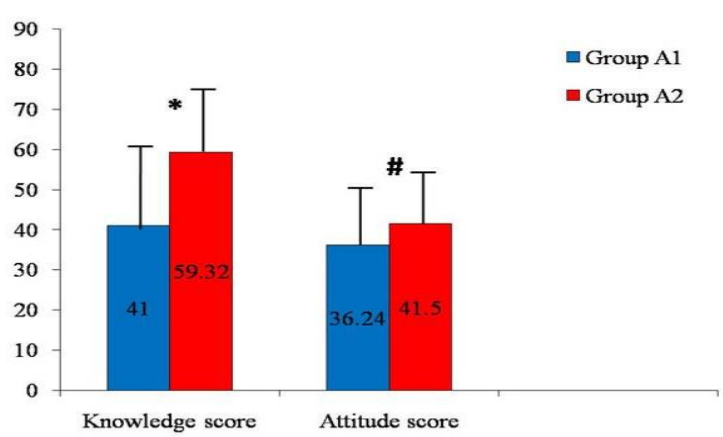

*P $<0.05$ by paired t-test, \# $\mathrm{P}<0.05$ by Wilcoxon matched pairs signed rank test. Knowledge scores is in percentage and attitude scores is in absolute number out of 75 .

Figure 2: Comparisions of knowledge and attitude scores in participants before and after attending seminar on EC.

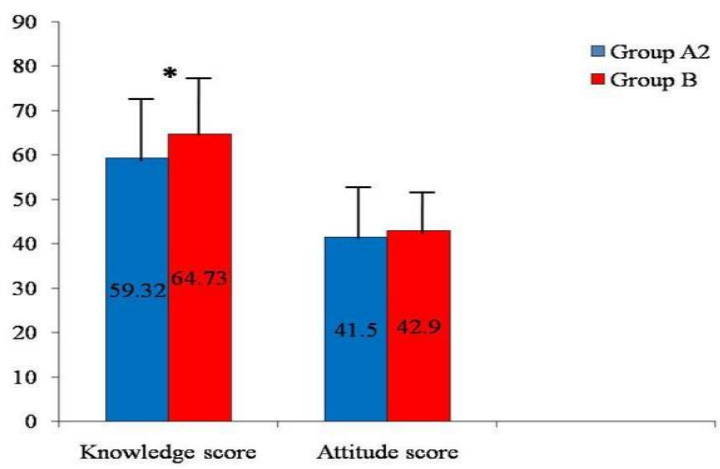

*P $<0.05$ by unpaired t-test. Knowledge score is in percentage and attitude scores is in absolute number out of 75 .

Figure 3: Comparisons of knowledge and attitude scores between study participants.

In present study, we evaluated knowledge and attitude about EC in undergraduate medical students. One hour objective based seminar on EC to group A students significantly increased their knowledge and attitude scores. This shows importance of objective based seminar for providing complete information.

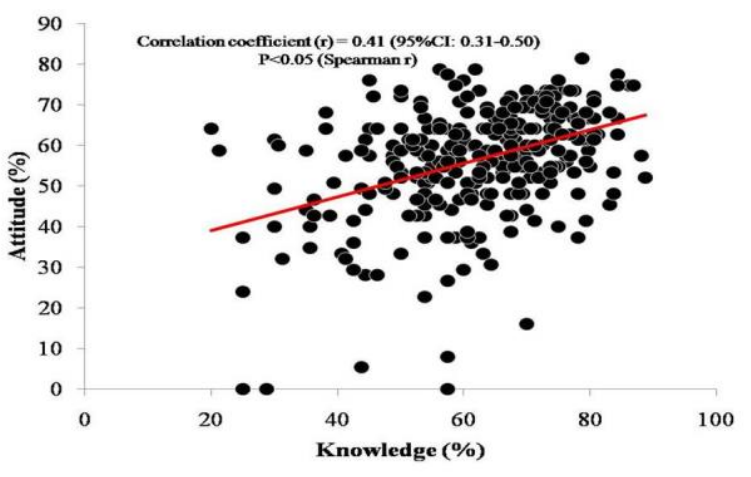

Figure 4: Correlation between knowledge and attitude of study participants.

After providing information, data of 146 students along with 162 students of group B were analyzed for overall assessment. Around 90\% participants were not able to describe about EC and different methods of EC. Only $10 \%$ participants were able to describe IUD as method of EC. In one Indian study, $40 \%$ undergraduate students were able to describe IUD as a method of EC. ${ }^{10}$ In present study, 50\% participants said that EC act as an abortifacient as compared to $25.5 \%$ and $8.1 \%$ participants from other studies. ${ }^{10,11}$ Knowledge about time limit of administration, effectiveness and common side effects of EC was better in our participants. This may be due to provided more importance to these issues during advertisement of EC. We covered some special issues those are common in clinical practice. Amongst all, $60.4 \%$ participants correctly mentioned that pregnancy test is not necessary for providing EC. EC is used to prevent the pregnancy and it does not induce abortion if woman is pregnant. There is no evidence for harmful effects of EC pills on pregnancy. ${ }^{12}$ Only $74.7 \%$ participants correctly mentioned that EC cannot prevent the sexually transmitted diseases. This is necessary when you are suggesting EC. Chances of sexually transmitted diseases are high during unprotected intercourse and EC only prevents unwanted pregnancy not the sexually transmitted diseases. Health care professional should provide this information to the users of EC. Only $47.1 \%$ students thought that IUD is effective as EC. Students should be taught about different methods of EC. IUD is effective even after fertilization occurs and its use provides benefit of regular contraception for long duration. ${ }^{12}$ Women should be motivated for use of regular contraception by health care professional and option of IUD should always be provided for EC. ${ }^{13}$ Amongst all $41.6 \%$ participants were able to mention that EC pills should be repeated if vomiting occurs within 2 hours of administration. Nausea and vomiting are common side effects of EC pills. ${ }^{14}$ If vomiting occurs within 2 hours of administration of EC pills, full doses should be repeated and this instruction should be given to the patient as it may reduce effectiveness of EC. ${ }^{15}$ Being future health care professionals, undergraduate students should be taught these kinds of special issues related with EC. Gender, religion, domicile, education status and 
socioeconomic status have significant impact on unwanted pregnancy and use of contraception. ${ }^{7}$ In the present study, only academic year showed significant difference in knowledge. For obvious reason, final year students and interns have more knowledge than first and second year students. Final year students and interns have many opportunities to learn about EC and its practical aspects. Overall knowledge was still lower in final year and intern students that shows requirement of providing them training on EC. As knowledge about side effects of EC was good among participants their attitude for benefits vs. risk profile of EC was positive. More than half participants felt that EC discourages use of regular contraception. Easy availability of EC pills and its effectiveness in prevention of pregnancy after unprotected intercourse may discourage the use of regular contraceptive methods. Repeated use of EC pills is not recommended due to increased risk of side effects. ${ }^{16}$ However, pre-coital use of contraceptive pill is shown to be efficacious, safe and acceptable, it may warrant revision of current recommendations. ${ }^{13}$ Around one third participants believed that use of EC promotes promiscuity. Users should be warned for the fact that EC does not provide benefit for sexually transmitted diseases as the condom provide. Proper counselling should be done. So, they would avoid this risk taking behaviour. Amongst all, $58.1 \%$ participants believed that EC should be available with prescriptions only. More than eighty percent students agreed to discuss about EC with friends and relatives. Being future doctors, the undergraduate students should be taught all basic and special aspects of EC. As shown in Figure 3, higher knowledge improves the attitude. Results of this study are depended on the responses of students of our institute and are not applicable to students of other institutes or universities.

\section{ACKNOWLEDGEMENTS}

Author would like to thank Indian Council of Medical Research, New Delhi for selecting this project as a part of Short Term Studentship Program 2013 and providing scholarship to the student.

Funding: No funding sources

Conflict of interest: None declared

Ethical approval: The study was approved by the Institutional Ethics Committee

\section{REFERENCES}

1. Chaudhuri SK. Editor. Practice of fertility control, $7^{\text {th }}$ ed. New Delhi: Elsevier. 2008;170.

2. Ahmed FA, Moussa KM, Petterson KO. Assessing knowledge, attitude, and practice of emergency contraception: a cross-sectional study among Ethiopian undergraduate female students. BMC Public Health. 201212:110.

3. Chopra S, Dhaliwal L. Knowledge, attitude and practices of contraception in urban population of
North India. Arch Gynecol Obstet. 2010;281(2):273-7.

4. Trussell J, Stewart F, Guest F. Emergency Contraceptive Pills: a simple proposal to reduce unintended pregnancies. Fam Plann Perspect. 1992;24:269-73.

5. Tesfaye T, Tilahun T, Girma E. Knowledge, attitude and practice of emergency contraceptive among women who seek abortion care at Jimma University specialized hospital, southwest Ethiopia. BMC Womens Health. 2012;12:3.

6. Parey B, Addison L, Mark JK, Maurice B, Tripathi $\mathrm{V}$, Wahid S, et al. Knowledge, attitude and practice of emergency contraceptive pills among tertiary level students in Trinidad: a cross-sectional survey. West Indian Medical Journal. 2010;59(6):650-5.

7. Dixit P, Ram F, Dwivedi LK. Determinants of unwanted pregnancy in India using mathced casecontrol designs. BMC Pregnancy Childbirth. 2012;12:84.

8. International Consortium for Emergency Contraception: Emergency Contraceptive Pills. 2nd edition. Washington, DC: US Department of Health; 2004.

9. Schwarz EB, Gerbet B, Gonzales R. Needs for emergency contraception in urgent care settings. Contraception. 2007;75:285-8.

10. Giri PA, Bangal VB, Phalke DB. Knowledge and Attitude of Medical Undergraduate, Interns and Postgraduate Students in India Towards Emergency Contraception. N Am J Med Sci. 2013;5(1):37-0.

11. Singh S, Mittal S, Anandalakshmy $P N$, et al. Emergency contraception: Knowledge and views of doctors in Delhi. Health Popul Perspect Issues. 2002;25:45-54.

12. Linden JA. Clinical practice. Care of the adult patient after sexual assault. N Engl J Med. 2011;365(9):83441.

13. Cleland K, Zhu H, Goldstuck N, et al. The efficacy of intrauterine devices for emergency contraception: a systematic review of 35 years of experience. Hum Reprod. 2012;27(7):1994-0.

14. Chen QJ, Xiang WP, Zhang DK, Wang RP, Luo YF, Kang JZ, et al. Efficacy and safety of a levonorgestrel enteric-coated tablet as an over-the-counter drug for emergency contraception: a Phase IV clinical trial. Human reproduction. 2011;26(9):2316-21.

15. Roey MM. Emergency contraception: A simple, safe, and effective approach to preventing pregnancy after unprotected intercourse. BC Medical Journal. 2002; 44(1):30-5.

16. Halpern V, Raymond EG, Lopez LM. Repeated use of pre- and postcoital hormonal contraception for prevention of pregnancy. Cochrane Database Syst Rev. 2010;(1):7595.

Cite this article as: Gajera AN, Barvaliya MJ, Shukla A, Tripathi CB. Knowledge and attitude towards emergency contraception among undergraduate medical students. Int J Basic Clin Pharmacol 2017;6:955-61. 